\title{
Optimal targets for India's per capita electricity use and energy mix
}

\author{
T. S. Gopi Rethinaraj* and Dilip R. Ahuja
}

Economic growth and human development are generally based on the assumption of corresponding increase in per capita energy use. The Economic Survey 2018-19 published by the Ministry of Finance, Government of India, has recommended a fourfold increase in the country per capita primary energy use from the current level to achieve the human development index (HDI) target of 0.8. The supply and environmental challenges for achieving such a high level of per capita primary energy use are formidable, if not insurmountable. Development experience of Sri Lanka, and Kerala suggests that high level of human development is possible even at lower per capita energy use, if complemented by adequate public investment in health and education. With a per capita electricity use of $1500 \mathrm{kWh}$ by 2030 and $2500 \mathrm{kWh}$ by 2050, India can achieve significant improvement in human development from the present level without imposing a large energy footprint.

Keywords: Human development, economic growth, optimal targets, primary energy use, per capita electricity use.

LENIN once remarked 'communism is Soviet power plus electrification' and wanted a socialist Russia with massive networks of electric power stations to serve as the model for development in Europe and Asia ${ }^{1}$. Economic growth and human development are generally premised on the idea of energy abundance and continue to influence policy in many countries, including India. The Economic Survey 2018-19 tabled in the Parliament by the Ministry of Finance, Government of India (GoI) last year relies on the tautology that improving per capita income and human development requires a corresponding rise in per capita energy use ${ }^{2}$. The Survey noted that increasing India's real per capita GDP to US\$ 5000 will need an increase in per capita energy use by a factor of 2.5 , while raising the country's human development index (HDI) score to 0.8 will entail a fourfold increase in per capita energy use. There is a strong correlation between energy use and economic growth across countries, but only up to a certain threshold, beyond which its effect is marginal. Empirical data suggest that energy is a necessary but an insufficient condition for economic growth and human development. In this article we examine whether India can achieve the human development goal set in the Economic Survey 2018-19 without the large increase in per capita energy use it assumes will be needed. If so, how do we approach the question of setting optimal targets for per capita energy use and energy mix in India that is also compatible with supply and environmental constraints?

T. S. Gopi Rethinaraj is at the Divecha Centre for Climate Change, Indian Institute of Science, Bengaluru 560 012, India; Dilip R. Ahuja lives at 3, First Main Road, BEL Layout, First Block, Vidyaranyapura, Bengaluru 560 097, India.

*For correspondence. (e-mail: gopir@iiisc.ac.in)

\section{Human development index and energy use}

HDI is a convenient proxy for average national wellbeing even though it does not factor in prevailing income inequalities, poverty levels and gender disparities within countries. There is also a growing use of happiness surveys to measure well-being based on reported selfsatisfaction, but they are less reliable and highly subjective $^{3}$. The United Nations Development Program (UNDP) has used HDI since the 1990s to capture the barest minimum features of human development on a scale of 0 to 1 . It is a composite index that summarizes a country's average achievements in three basic categories of human development: health, education and living standards. Health is quantified by average life expectancy at birth, education by the mean of years of schooling for adults aged 25 years using a combination of adult literacy rate, primary, secondary, and tertiary enrolment ratios, and living standards by per capita GDP in purchasing power parity currency. HDI is the geometric mean of normalized indices for each of these three categories of human development ${ }^{4}$.

Countries are listed and ranked according to these metrics in the annual HDI reports published by UNDP. In the 2019 HDI report ${ }^{5}$, India with a HDI score of 0.647 was in the 129th position out of the 189 listed countries, and placed in the category of countries with 'medium' level human development. China with a HDI of 0.758 was in the 85 th position and in the category of countries with 'high' level human development. India transitioned from what is now considered 'low' to the present category of 'medium' level human development in 2002. Achieving the HDI target of 0.8 set in the Economic Survey 2018-19 will place India at the lower end of the spectrum 
of countries with 'very high' level of human development. The 2019 HDI report has listed 62 countries in this category, ranging from Seychelles with a HDI of 0.801 to Norway with a HDI of 0.954 .

It is not difficult to understand the reasoning behind the recommendation for increased per capita energy use made in the Economic Survey 2018-19. Most countries in the category of 'very high' level human development have high per capita GDP and high per capita energy use. The Survey relies on simple linear regression, which shows an increase of US\$ 145 in per capita GDP for every gigajoule (GJ) increase in primary energy use. This implies that increasing India's current annual per capita primary energy use by a factor of 2.5 , from 24 to $60 \mathrm{GJ}$, leads to a per capita GDP of US\$5000 at 2010 price levels. Likewise, the Survey curve fitted data on HDI and per capita primary energy use to suggest that countries with per capita primary energy use of 100 GJ on an average have a HDI of around 0.8 .

Nevertheless, any number chosen without adequate rationale, even if backed up with statistical armour, will appear to be arbitrary. This is something that the leadership of the Department of Atomic Energy (DAE), GoI, has done for many years to bolster its case for a large nuclear programme. Chidambaram ${ }^{6}$ (Former Chairman, Atomic Energy Commission (AEC), DAE, GoI) suggested a minimum of $4000 \mathrm{kWh}$ per capita electricity consumption using a catchy advertising slogan to explain his rationale: 'dil maange more' (heart desires more). His successor Anil Kakodkar echoed a similar refrain recently ${ }^{7}$ and recommended a 30 -fold increase in nuclear capacity from the present level to achieve a target of $5000 \mathrm{kWh}$ per capita electricity use.

Aspirational targets are less useful for setting policy goals and guiding development priorities. A more realistic target pertinent to our discussion has been provided by Goldemberg et al. ${ }^{8}$, which is one of the earliest attempts to quantify minimum per capita energy requirement for developing countries in warm tropical climate like India. They concluded after a rigorous accounting of minimum energy for various human needs that a total of 33 GJ per capita energy use, including $1840 \mathrm{kWh}$ per capita electricity use would be adequate to ensure basic human comfort and enable higher human development in developing countries than the prevailing levels more than three decades ago (note 1). The suggested benchmarks for primary energy and electricity were based on the 1970s energy technologies and conversion efficiencies. With current efficiency improvements and appliance standards, they should provide for more than the authors' original estimates.

Some countries have achieved impressive development outcomes with frugal energy use. Cuba and Sri Lanka have a HDI of 0.777 and 0.776 with a relatively low per capita primary energy use of 37 and 19 GJ respectively. There are also examples of resource-rich countries with a high per capita energy use, but lower or only comparable
HDI scores than many rich and middle-income countries. Russia and Turkmenistan with a per capita energy use of 238 and 318 GJ have a HDI score of 0.822 and 0.708 respectively, while Argentina and Romania with a per capita energy use of 93 and 75 GJ have a HDI score of 0.832 and 0.813 respectively.

This underlines the importance of country-specific challenges and opportunities to improve human development. Recent data ${ }^{9}$ on per capita primary energy use of 182 countries show that 113 countries have per capita consumption above the $33 \mathrm{GJ}$ minimum suggested by Goldemberg et $a l .{ }^{8}$, while 71 countries, including India are below this threshold. The actual per capita energy use may be higher and at least 15-20 more countries will be able to meet the $33 \mathrm{GJ}$ threshold if non-commercial biomass energy use, which is significant for many developing countries like India, is also included. There are 56 countries with a per capita use above $100 \mathrm{GJ}$, the target recommended in the Economic Survey 2018-19. India's HDI of 0.647 for a per capita primary energy use of 24 GJ suggests that there is adequate scope for improving the HDI further with only a modest increase in the per capita energy use (Figure 1).

We could look at examples of countries such as Sri Lanka, Cuba, Romania and Argentina for achieving the human development target set in the Economic Survey 2018-19, but without imposing a huge energy increase requirement. The development trajectories of various States and Union Territories in India, and their per capita energy use trends offer useful insights. Kerala with a low per capita electricity use of $757 \mathrm{kWh}$ has the highest HDI score in the country and consistently performed well in many socio-economic indicators than states with a higher per capita electricity use like Gujarat (Figures 2 and 3). HDI was devised to highlight the importance of human resources and their capabilities as better criteria to assess development outcomes. While per capita income and per capita energy use have instrumental utility in achieving those outcomes, massive public spending and investment in health and education allow people in countries with low per capita GDP and low per capita energy use to achieve relatively high levels of human development.

\section{Choosing optimal targets}

Per capita primary energy use by itself is unimportant. Reliable and affordable access to energy services is more important to enable full development of human potential. Primary energy in most cases is not directly consumed and less helpful to understand its impact on human development. For example, a coal plant running at $40 \%$ thermal-to-electric conversion efficiency dissipates threefifth of the energy content in fuel as waste heat, while only two-fifth of the energy content are actually used as electricity. Diesel, gasoline and other distillates from 
crude oil have roughly the same energy content as the feedstock, but the derived products do not include energy input for distillation and refinery losses. There are also significant differences among various primary energy sources used for electricity generation. Although the Economic Survey 2018-19 uses per capita primary energy use in its analysis, per capita electricity use offers better clarity for evaluating HDI outcomes.

Per capita electricity use varies across countries (Figure 4). However, there appears a threshold minimum below which ensuring a reasonable standard of living and economic opportunities becomes difficult. Every country has a unique set of energy requirements given its geography, climate, spread and portfolio of economic activities. In many developed countries, annual per capita electricity

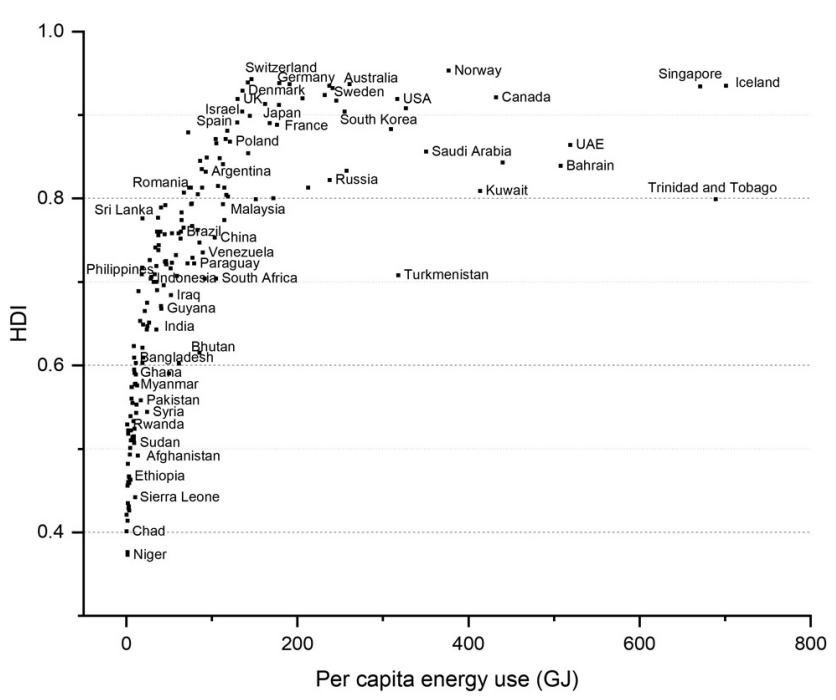

Figure 1. Cross-country comparison of human development index (HDI) versus per capita primary energy use in 2017.

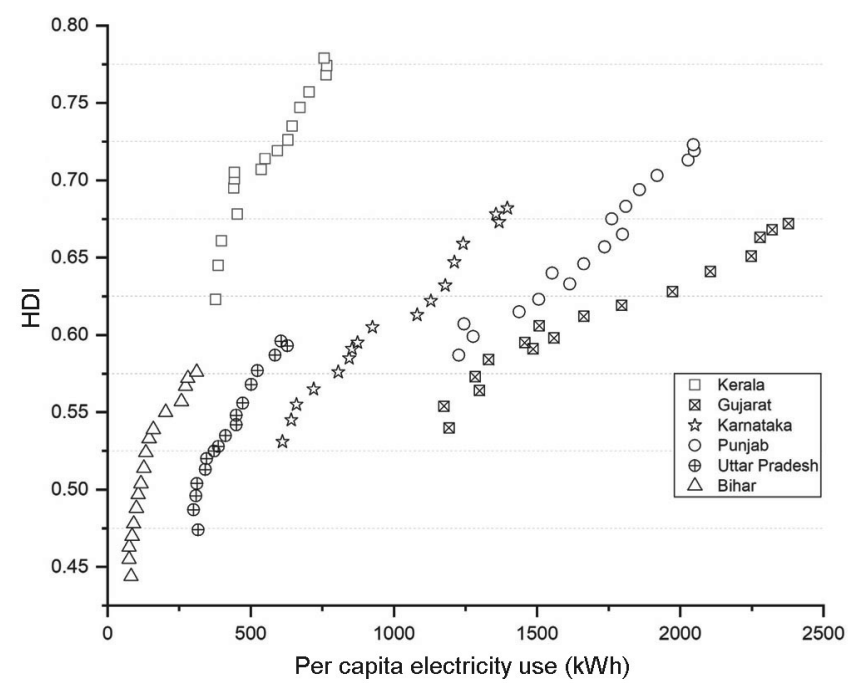

Figure 2. Evolution of HDI versus per capita electricity use in Kerala, Gujarat, Karnataka, Uttar Pradesh and Bihar, India from 2002 to 2018. use exceeds $7000 \mathrm{kWh}$ compared to middle-income countries, where it mostly ranges from 2500 to $4000 \mathrm{kWh}$. Per capita electricity use in India is around $1200 \mathrm{kWh}$, while in China, Germany and the United States it is 5200, 7300 and $13,000 \mathrm{kWh}$ respectively (note 2 ). The per capita electricity use is $3100 \mathrm{kWh}$ in Argentina, $3000 \mathrm{kWh}$ in Romania, $1400 \mathrm{kWh}$ in Cuba, and $760 \mathrm{kWh}$ in Sri Lanka (Figure 5). Although India has made significant progress in increasing per capita electricity use since 1947, when it was just $16 \mathrm{kWh}$ (ref. 10), it is still below the world average of about $3400 \mathrm{kWh}$.

India's current energy predicament is grim. Around $60 \%$ of households in the country rely solely on

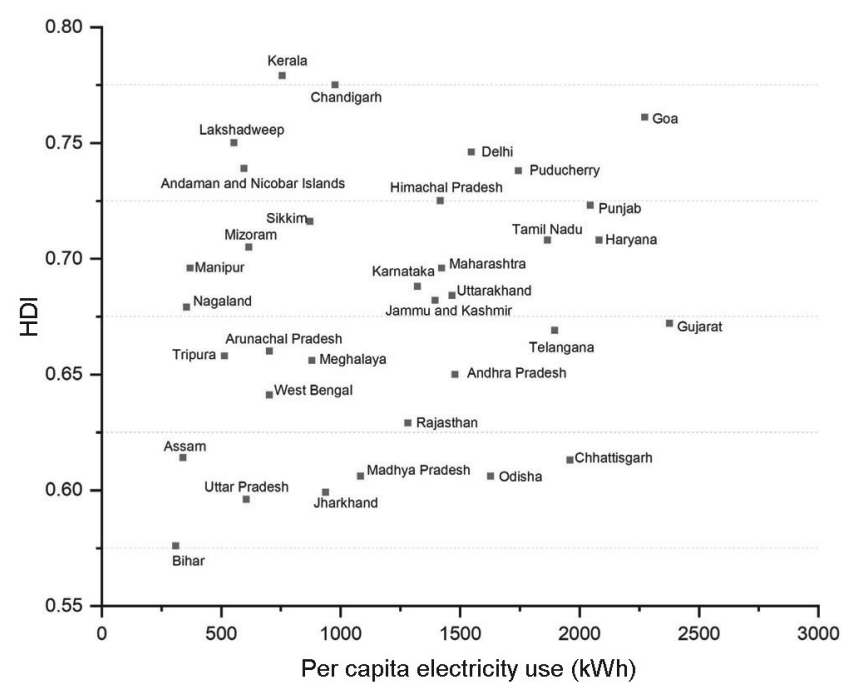

Figure 3. HDI versus per capita electricity use for various States and Union Territories (UTs) of India in 2018. The UTs of Dadra and Nagar Haveli, and Daman and Diu (their per capita electricity use is seven and 15 times higher than the national average respectively) have been excluded in this plot.

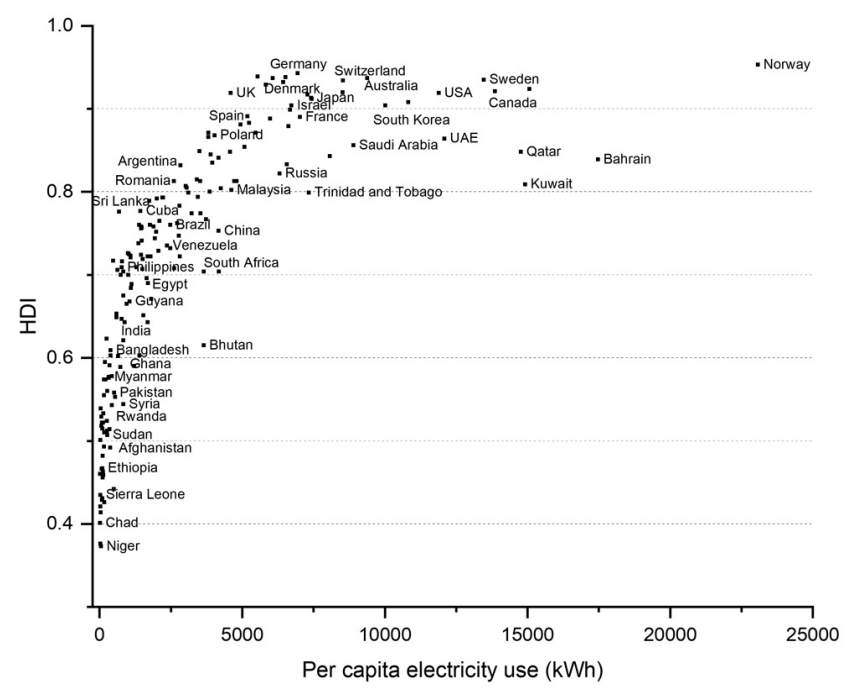

Figure 4. Cross-country comparison of HDI versus per capita electricity use in 2017. 


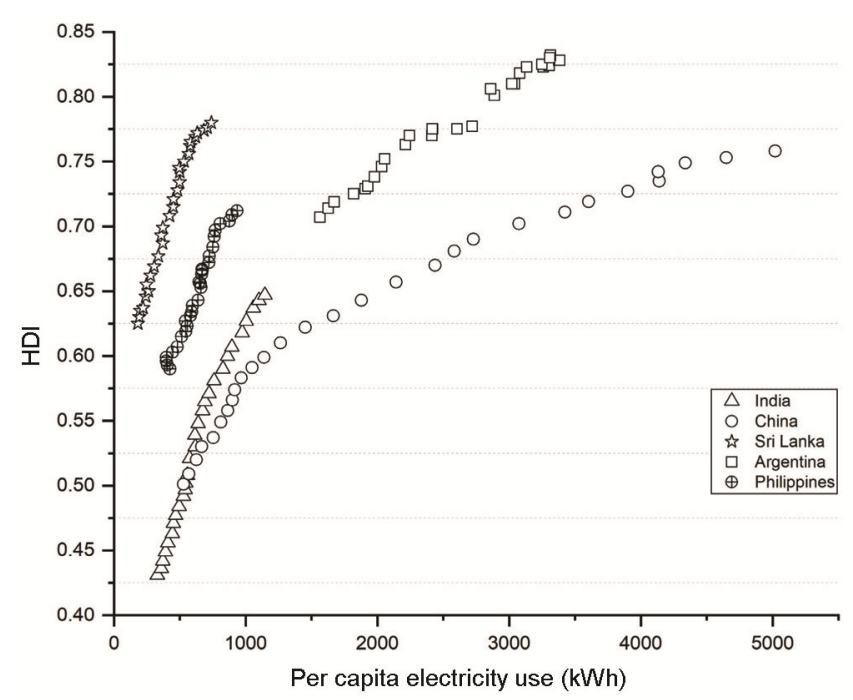

Figure 5. Evolution of HDI versus per capita electricity use in India, China, Sri Lanka, Argentina, and the Philippines from 1990 to 2018.

firewood, crop residue and animal dung for cooking, while $15 \%$ of the population does not have any access to electricity ${ }^{11}$. Even for those who have access to electricity connection, the quality of supply is poor. Load shedding is common in urban areas, while villages in many states do not get electricity for long hours every day. Over half of electrified households in rural areas of Uttar Pradesh, Bihar, Madhya Pradesh, Jharkhand, Odisha and West Bengal have $12 \mathrm{~h}$ of power cuts every day ${ }^{12}$.

The paraphernalia of battery and diesel back-ups that are ubiquitous in urban residential and commercial areas will not be needed if electricity supply were reliable. Increasing per capita electricity use is certainly critical for industrial expansion and agriculture modernization to lift millions of families out of the poverty trap. However, the issue here is what future level of per capita electricity use should be set as a realistic target for policy action. Scenarios examining various future paths have typically set unrealistic per capita electricity use targets for India based on international experience. Per capita use has to increase primarily to provide access to those completely deprived and those who are provided only intermittently. This should proceed apace with energy conservation and efficiency improvements. The goal is to achieve as high HDI as possible without concurrently increasing per capita electricity use.

It is unnecessary to try and peg a target to that of other countries. We suggest a more realistic per capita electricity use target of $1500 \mathrm{kWh}$ by 2030 and increasing it to $2500 \mathrm{kWh}$ by 2050 , taking into account the expected increase in population and constraints for increased electricity generation in India. These two targets are neither unreasonable, nor do they suggest profligacy. The target for 2030 is still more than $50 \%$ below current global average. Even the target for 2050 is $50 \%$ lower than cur- rent Chinese per capita use and significantly below the global average. The suggested increases are expected to have an appreciable impact in improving the quality of life and providing economic opportunities for those left behind by post-1991 reforms.

The challenge then is to formulate a credible national energy policy to achieve the above goals by 2050 , a timeline that will be useful on three counts. First, the power projects that are under construction or being planned now will still be operational around that time and determine the eventual energy mix for electricity generation. Second, acting on its own interest or in response to a potentially binding future international treaty to reduce carbon emissions even beyond the Paris commitment, India will have to significantly move away from carbonintensive fuels for power generation by that time. Third, the demographic transition from high to low fertility is expected to stabilize India's population by the middle of this century.

India is expected to overtake China as the world's most populous country by 2027 (ref. 13). According to projections using medium fertility variant assumptions by the United Nation Population Division, India's population will reach 1.5 billion by 2030 and stabilize at 1.6 billion by 2050 . The country's total fertility rate is now at 2.2 with 14 states at or below replacement level fertility ${ }^{14}$. However, there are still a handful of populous states having fertility rates above 2.1 that will continue to add to the population stock. Bihar is the only state with a fertility rate above 3 . States with better educational and health indicators have relatively high HDI scores and have been able to control population growth more effectively. Kerala's example is noteworthy given that it has the highest HDI in the country despite a low per capita electricity use compared to richer and more industrialized states (Figures 2 and 3).

Achieving per capita electricity use of $2500 \mathrm{kWh}$ by 2050 requires a 2.5 -fold increase in power generation from the present level, while reaching the medium-term goal of $1500 \mathrm{kWh}$ requires 1.5 -fold increase in generation (note 3 ). Historically, addition of electricity capacity has been slow in India due to market regulations, insufficient investment, difficulties in obtaining environmental approvals and public acceptance for major power projects. Since energy projects are subject to various time lags, initiatives to improve efficiency and conservation efforts should proceed in tandem. Realizing these goals requires substantial investment in generation, transmission and distribution infrastructure.

While there are several pathways to realize the 1500 and $2500 \mathrm{kWh}$ targets by 2030 and 2050 respectively, the evolution of optimal energy mix for electricity generation has significant implications for energy supply security and environmental sustainability. A major concern is the growing import dependence for energy fuels and technologies. Current import shares of fossil fuel consumption are 
$32 \%$ for coal, $55 \%$ for natural gas and nearly $85 \%$ for oil (note 4). Even the recent solar energy boom was driven primarily by imports from China. Import dependence for solar panels was more than $90 \%$ during the three fiscal years from 2015 to 2018, when large generating capacity was added ${ }^{15}$. The wind energy sector is not dependent on imports as India is in one of the main manufacturing hubs with many leading turbine suppliers ${ }^{16}$. Future nuclear expansion will also largely depend on imported uranium because domestic production relies on low-grade ores that are relatively expensive to mine and process. Therefore, sources for electricity generation in the future and reliability of their supply will be critical to sustain the $2500 \mathrm{kWh}$ per capita electricity use target suggested here.

\section{Sources for electricity generation}

Since oil is primarily used for transport and is not significant for electricity generation in India, except for captive generation and back-up diesel generators in commercial and residential areas, the sources relevant to future electricity generation in the country are coal, natural gas, renewables and nuclear. Of the $370 \mathrm{GW}$ of current total installed electricity generation capacity ${ }^{17}$, coal plants account for $55 \%$, large hydro $12 \%$, renewable sources $24 \%$, gas $7 \%$ and nuclear $2 \%$. The percentage share of actual power generation in 2019 were $^{18}$ : coal plants 73 , hydropower 10.4 , renewables 8.7 , gas 4.6 , nuclear 2.9 and diesel 0.5 .

To meet the stated per capita electricity use targets, total installed electricity capacity will have to reach nearly $500 \mathrm{GW}$ by 2030 and around $750 \mathrm{GW}$ by 2050 . Targets for capacity addition also depend on the desirable energy mix to achieve the per capita electricity use targets. The composition of fuel mix compatible with future energy security and environmental goals requires increasing domestic coal production while simultaneously increasing the share of renewable sources and nuclear energy for power generation. Even though new coal plants are finding it difficult to economically compete with renewable sources, they are likely to retain the largest share in the generation through 2050. Even with a significantly reduced share of about $50 \%$, coal use will continue to increase in absolute terms. Whether domestic coal production can be increased on time to fuel the planned expansion is difficult to prognosticate.

For long India's coal policy suffered from complacency on account of the large domestic coal resources (proven reserves and indicated reserves) currently estimated at around 325 billion metric tonnes ${ }^{19}$, which under the current rate of production could last for more than 300 years. However, this large estimate does not indicate how much of it is technically or economically recoverable. This includes coal located up to a depth of $1200 \mathrm{~m}$, although current mining in India is limited to $300 \mathrm{~m}$. The new estimates suggest not more than $50 \%$ of this could be recovered, which is still a large resource for electricity generation. Many of India's coal provinces lie in forested or heavily populated areas. Other bottlenecks for increasing domestic coal production are poor infrastructure (rail network and port capacity) and social resistance caused by displacement of tribal communities from the coal belts. Not surprisingly, import of coal has grown considerably in recent years. Even if the planned coal-fired thermal power projects are completed, current supply situation remains precarious leaving many future coal plants more dependent on imports. This is likely to increase the price of electricity from coal. Despite its increasing cost and environmental problems, coal will remain the mainstay of India's electricity supply, certainly through 2030 and likely through 2050, because of its dispatchability.

Use of natural gas for electricity generation (mostly peaking plants and captive generation) has also increased recently in India because of lower capital cost and environmental benefits. India's gas reserves are modest and estimated at around 1300 billion cubic metres ${ }^{20}$. Domestic production is typically allotted on priority to fertilizer plants, petrochemical units, $\mathrm{CNG}$ consumption and other uses, leaving only the remaining (30-40\%) for electricity generation. Iran and Qatar have the potential to become major sources of piped natural gas supply for India, but international political difficulties continue to be a major obstacle for this project. Given the current political difficulties of building overland pipelines from the Middle East to India via Pakistan, LNG imports have gained precedence even though they are more expensive than piped gas. Current Indian imports are $6.8 \%$ of the global LNG trade $^{20}$ and recent developments have driven up the spot market price for LNG. Unless India negotiates flexible, long-term contracts, LNG fuel purchased in the spot market is an expensive form of electricity and could limit the role of natural gas in electricity generation.

Even though hydropower is the largest source of nonfossil electricity, further expansion is limited due to societal challenges. Therefore, increased use of renewable energy sources such as solar and wind is a desirable goal for India. Electricity generation from these renewable sources has increased considerably in recent years because of a supportive policy environment, and low capital and operating costs. They remain the primary hope for cheaper and faster decarbonization of the electricity sector. India is one of the few countries with abundant sunshine with an annual average insolation varying from 4 to $7 \mathrm{kWh} / \mathrm{m}^{2} /$ day with 250-300 clear sunny days per year. While the pace of renewable capacity additions and generation has been remarkable in recent years, increasing its role further requires sustained policy support for longterm financial viability. Interestingly, Goldemberg et al. ${ }^{8}$ never anticipated that solar and wind would become the cheapest source of electricity globally in 35 years, and 
left them out totally in their future projections of energy supply.

Finally, the role of nuclear power in the evolving energy mix to meet the suggested per capita electricity use targets by 2030 and 2050 remains unclear. India has been pursuing an indigenous 'three-stage programme' to develop long-term electricity supply using a mix of indigenous heavy-water reactors, breeder reactors and thorium-fuelled reactors, in addition to imported lightwater reactors from Russia, United States and France. The indigenous nuclear programme is aimed at eventually utilizing the large thorium reserves in the country using a closed fuel cycle path with dubious economic and energy security benefits. However, this policy remains deeply entrenched due to the international isolation and sanctions that India faced after the 1974 nuclear test. The 2005 civilian nuclear agreement with the United States opened doors for India to import uranium as well as reactors from various international vendors. Following India's normalization of nuclear relations with the rest of the world, DAE announced an ambitious target to build $63 \mathrm{GW}$ of nuclear capacity by 2032 . International developments after the 2011 Fukushima nuclear accident, rising costs of nuclear power, India's nuclear liability law and the present government's preoccupation with renewable energy have dampened the prospects for nuclear electricity generation in the country.

The best-case nuclear scenario for 2030 is the timely completion of the nine reactors $(6.7 \mathrm{GW})$ under construction and 12 reactors $(9 \mathrm{GW})$ for which DAE has secured financial approval from the government, in addition to the 22 operating reactors $(6.7 \mathrm{GW})$. These add up to about $23 \mathrm{GW}$ of nuclear capacity, which is just one-third of DAE's original target for 2032. DAE also has plans for 23 additional reactors $(26.7 \mathrm{GW})^{7}$, but their approval status is unknown. Nuclear expansion is arguably desirable on environmental grounds and as a potential hedge against unforeseen future supply difficulties for base-load generation, but the social and economic costs appear to far outweigh those benefits. In addition, the siting options for a large nuclear expansion beyond $22 \mathrm{GW}$ in India are limited. Land and cooling-water constraints in the interior had directed the choice of locating new sites in coastal areas which face frequent flooding risks. Given these risks and challenges for securing sites with low population density for new projects and building a permanent geological nuclear waste repository, it would be prudent to freeze nuclear capacity at $23 \mathrm{GW}$. While the economic challenges influence the government's support for funding and financial approvals, organizational opaqueness and the culture of secrecy shape social attitudes toward nuclear power. There is currently a large trust deficit and it may require more than public relation campaigns to assuage public perceptions. It is likely that the role of nuclear power will continue to remain marginal for India's electricity supply through 2050.

\section{Conclusion}

Poverty alleviation in India requires at least 2-3 decades of growth of $7 \%$ or more, which requires a matching rate of growth in infrastructure facilities, of which electric power generation ranks highest in the order of priority. Even if India were to settle down for the suggested lower per capita electricity use compared to other developing countries, total generation has to more than double from the current level to achieve our suggested target of $2500 \mathrm{kWh}$ by 2050 , and increase by nearly $50 \%$ in the medium term to achieve the $1500 \mathrm{kWh}$ target by 2030 . Achieving these targets critically depends on the optimal energy mix for electricity generation that is also compatible with India's supply constraints and long-term climate goals.

Empirical evidence suggests that it is possible to achieve a HDI target of 0.8 or closer to it without concomitant rise in per capita electricity use. Since per capita income is one of the three inputs for computing HDI, it would be unrealistic to set targets above 0.85 or 0.9 based on closing the income gap between India and rich societies. It is also clear that reaching the HDI target set in the Economic Survey 2018-19 is possible by largely improving health and educational outcomes for which modest increases in per capita income and per capita electricity use would suffice. Development experience of Sri Lanka and Kerala suggests that a HDI of 0.8 can be reached by just maximizing health and educational attainment with existing levels of per capita electricity use and per capita income. These observations underline the importance of the government's priority and responsibility in the spheres of health and education. Inadequate public investment in these two critical sectors leaves a largely poor population at the mercy of private profiteers, resulting in suboptimal human development and low HDI.

\section{Notes}

1. The authors' estimated $1049 \mathrm{~W}(\sim 1 \mathrm{~kW})$ of total energy use per capita including $210 \mathrm{~W}$ of electricity is converted to more familiar units, viz. gigajoule (GJ) and kilowatt hour (kWh). For primary energy use, GJ is more appropriate than $\mathrm{kW}$, which is a unit of power and not energy.

2. Current per capita electricity use for countries is derived using gross electricity generation in 2019 from the BP Statistical Review of World Energy 2020, and population estimates for countries provided by the United Nations Population Division for 2019. Per capita electricity use for Cuba is derived from US EIA International Statistics and United Nations Population Division for 2017.

3. India's gross electricity generation in 2019 was around $1500 \mathrm{TWh}$. Per capita use of $2500 \mathrm{kWh}$ for a population of 1.6 billion by 2050 requires electricity generation of $4000 \mathrm{TWh}$. Per capita use of 1500 $\mathrm{kWh}$ for a population of 1.5 billion by 2030 requires electricity generation of $2250 \mathrm{TWh}$.

4. BP Statistical Review of World Energy 2020. The import share was computed using the ratio of domestic production to total consumption. 
1. Lenin, V. I., Collected Works (Progress Publishers, Moscow, 1964), vol. XXXI, pp. 513-518; http://soviethistory.msu.edu/ 1921-2/electrification-campaign/communism-is-soviet-power-electrification-of-the-whole-country/ (accessed on 5 July 2020).

2. MoF, Enabling inclusive growth through affordable, reliable and sustainable energy. In Economic Survey 2018-19, Ministry of Finance, Government of India, 2019, vol. 1, pp. 163-182; https:// www.indiabudget.gov.in/budget2019-20/economicsurvey/doc/ echapter.pdf (accessed on 4 July 2020).

3. Ortiz-Ospina, E. and Roser, M., Happiness and Life Satisfaction, May 2017; https://ourworldindata.org/happiness-and-life-satisfaction (accessed on 9 July 2020).

4. United Nations Development Program, Human Development Index; http://hdr.undp.org/en/content/human-development-index-hdi (accessed on 8 July 2020).

5. United Nations Development Program, Human Development Report, 2019; http:/hdr.undp.org/sites/default/files/hdr2019.pdf (accessed on 8 July 2020).

6. Chidambaram, R., Inaugural Lecture. In 30th Annual Programme for Senior Executives, National Institute of Advanced Studies, Bengaluru, 18 to 23 January 2016. Chidambaram has written and spoken on several occasions on the more-is-better philosophy.

7. Kakodkar, A., Lockdown lecture: dealing with energy needs in the context of climate crisis. Nehru Science Centre, Mumbai. Streamed live on 10 May 2020; https://youtu.be/qQ2WtD6CPfA (accessed on 9 July 2020).

8. Goldemberg, J., Johansson, T. B., Reddy, A. K. N. and Williams, R. H., Basic needs and much more with one kilowatt per capita. Ambio, 1985, 14, 190-200.

9. Primary Energy Data Source, 2017 Total energy use data from US EIA; https://www.eia.gov/international/data/world/total-energy/ more-total-energy-data (accessed on 4 July 2020); Population Data Source, 2017 Population data from UN; https://population.un.org/ wpp/Download/Standard/Population (accessed on 2 July 2020).

10. Central Electricity Authority, Growth of electricity sector in India from 1947-2017; http://www.cea.nic.in/reports/others/planning/ pdm/growth_2017.pdf (accessed on 14 July 2020).

11. Ritchie, H., Access to energy, OurWorldInData.org, 2019; https:// ourworldindata.org/energy-access (accessed on 9 July 2020).

12. Suparna Dutt D'Cunha, Modi announces ' $100 \%$ Village Electrification', But 31 million Indian homes are still in the dark. Forbes, 7 May 2018; https://www.forbes.com/sites/suparnadutt/2018/ 05/07/modi-announces-100-village-electrification-but-31-millionhomes-are-still-in-the-dark/\#3dd7ef6263ba (accessed on 14 July 2020).

13. United Nations Population Division; https://www.un.org/en/ sections/issues-depth/population/index.html (accessed on 12 July 2020).

14. Rukmini, S., As India moves to slow population growth, Bihar gets left behind. LiveMint, 7 July 2020; https://www.livemint. com/news/india/as-india-moves-to-slow-population-growth-bihargets-left-behind-1 1594110050215.html (accessed on 9 July 2020).

15. Economic Times, India's import dependence for solar equipment over 90 per cent in last 3 fiscal: Government, 19 July 2018; https://economictimes.indiatimes.com/industry/energy/power/indiasimport-dependence-for-solar-equipment-over-90-per-cent-in-last-3fiscal-government/articleshow/65055838.cms (accessed on 18 July 2020).

16. Verma, A., Leading wind turbine suppliers in India in 2019, 30 June 2020; https://www.saurenergy.com/solar-energy-blog/ leading-wind-turbine-suppliers-in-india-in-2019 (accessed on 18 July 2020).

17. Central Electricity Authority, Government of India, June 2020; http://www.cea.nic.in/reports/monthly/installedcapacity/2020/installed_capacity-05.pdf (accessed on 14 July 2020).

18. BP Statistical Review of World Energy 2020.

19. Sengupta, D., Coal India exploration arm adds 7.8 billion tonnes to proven coal reserves. Economic Times, 24 June 2020; https:// economictimes.indiatimes.com/industry/indl-goods/svs/metalsmining/coal-india-exploration-arm-adds-7-8-billion-tonnes-toproven-coal-reserves/articleshow/76562229.cms (accessed on 14 July 2020).

20. BP Statistical Review of World Energy 2020.

ACKNOWLEDGEMENT. We thank Prof. J. Srinivasan and Dr Shoibal Chakravarty for reading the draft and providing useful comments and Karthik Ganesan for help on some data sources.

Received and accepted 26 August 2020

doi: $10.18520 / \mathrm{cs} / \mathrm{v} 119 / \mathrm{i} 10 / 1620-1626$ 